\title{
A Modified Voltage Balancing Algorithm for the Modular Multilevel Converter: Evaluation for Staircase and Phase-Disposition PWM
}

\author{
Rosheila Darus, Student Member, IEEE, Josep Pou, Senior Member, IEEE, Georgios Konstantinou, Member, IEEE, \\ Salvador Ceballos, Ricard Picas, Student Member, IEEE, Vassilios G. Agelidis, Senior Member, IEEE
}

\begin{abstract}
This paper introduces a low complexity implementation of the voltage balancing algorithm aiming to reduce the switching frequency of the power devices in modular multilevel converters (MMCs). The proposed algorithm features a relatively simple implementation without any conditional execution requirements and is easily expandable regardless of the number of sub-modules (SMs). Two modulation techniques are evaluated, namely the staircase modulation and the phase-disposition pulsewidth modulation (PD-PWM) under the conventional and the proposed algorithm. Using a circulating current controller in an MMC with 12 SMs per arm, PD-PWM yields better results compared to the staircase modulation technique. The test condition for this comparison is such that the power devices operate at a similar switching frequency and produce similar amplitudes to the capacitor voltage ripples in both modulation techniques. The results are verified through extensive simulations and experiments on a low power phase-leg MMC laboratory prototype.
\end{abstract}

Index Terms-Modular multilevel converter, Modulation technique, Pulse-width modulation, Capacitor voltage balancing

\section{INTRODUCTION}

The modular multilevel converter (MMC) [1], shown in Fig. 1, has recently attracted significant research interest and has been applied to high-voltage direct current (HVDC) transmission [2]. Modular converters, such as the MMC, combine the advantages of multilevel power conversion including low harmonic distortion, low switching losses and fault tolerant operation with a relatively easy voltage balancing task and elimination of the dc-link capacitor [3], [4].

Major challenges associated with the MMC include voltage balancing of the SM capacitor voltages as well as control of the

R. Darus is with the Australian Energy Research Institute and the School of Electrical Engineering and Telecommunications, The University of New South Wales, Sydney, NSW, 2052, Australia, on study leave from Universiti Teknologi Mara, Malaysia (email: r.darus@student.unsw.edu.au, roshe678@tganu.uitm.edu.my)

G. Konstantinou and V. G. Agelidis are with the Australian Energy Research Institute and the School of Electrical Engineering and Telecommunications, The University of New South Wales, Sydney, NSW, 2052, Australia (e-mail g.konstantinou@unsw.edu.au, vassilios.agelidis@unsw.edu.au).

J. Pou is with the Australian Energy Research Institute and the School of Electrical Engineering and Telecommunications, The University of New South Wales, Sydney, NSW, 2052, Australia, on leave from the Technical University of Catalonia, Barcelona, 08034, Catalonia, Spain (e-mail: j.pou@unsw.edu.au, josep.pou@upc.edu).

S. Ceballos is with the Energy Unit, Tecnalia Research and Innovation, Derio, 48160, Basque Country, Spain (e-mail: salvador.ceballos@tecnalia.com).

R. Picas is with the Terrassa Industrial Electronics Group,Technical University of Catalonia, Terrassa, 08222, Catalonia, Spain (e-mail: ricard.picas@upc.edu

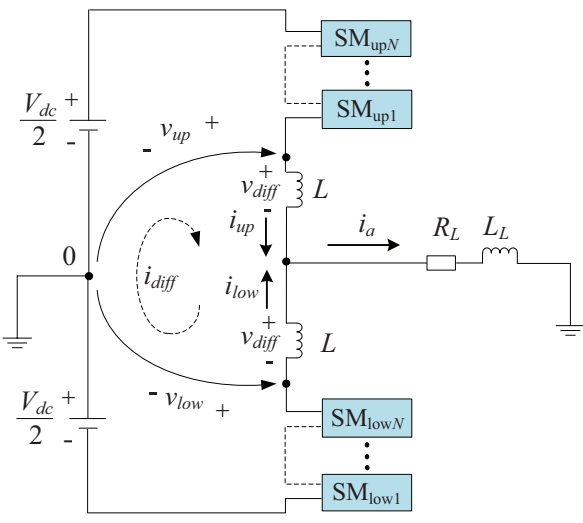

Fig. 1. Phase-leg of the MMC.

circulating currents [5]-[9]. Conventional voltage balancing algorithms are based on sorting the SM capacitor voltages; selection of the SMs to be connected or bypassed depends on the instantaneous values of the SM capacitor voltages and the direction of the arm currents [6]. An alternative approach utilises the approximately equal conduction times of phaseshifted pulse width modulation (PS-PWM) and adjusts the individual SMs in order to balance the capacitor voltages to the required value. These two methods are widely used in the available technical literature [10], [11]

In an effort to reduce the number of voltage sensors required in the MMC arms, estimation of SM capacitor voltages is also feasible [12]. A voltage balancing method that calculates the energy within the SMs and achieves voltage balancing over a number of fundamental cycles was proposed in [13] using staircase modulation. A hierarchical control structure with distributed control tasks using only the measurement of the arm currents was developed in [14]. Utilising equal SM conduction times and regulating the voltages of the most and least charged SM was also shown to provide satisfactory voltage balancing performance [15].

Voltage balancing algorithms based on sorting can cause excessive switching operations due to the continuous variation of the SM capacitor voltages within one switching period, resulting in higher losses. Various algorithms aimed at reducing the switching frequencies of the MMC have been proposed [16]-[18]. Modifying the execution time and priority of the voltage measurement and sorting tasks also leads to a reduction of the SM switching frequencies [16]. 
The algorithm of [17] reduces the switching frequency through two separate sorting stages, one for the connected SMs and one for the bypassed ones. The size of both groups changes depending on the number of connected and bypassed SMs, while additional calculations are required in the post-sorting stage to properly combine the groups and select the SMs, adding to the complexity of the implementation. The use of a maintaining factor as a multiplier to specific SM capacitor voltages, mainly determined by the arm current, is also shown to reduce the switching frequencies [18].

The selection of voltage balancing algorithm is closely tied to the PWM technique. Various modulation techniques have been applied to the MMC. Carrier-based pulse-widthmodulation (CB-PWM) techniques are the most common ones [19]-[22], but other techniques such as selective harmonic elimination (SHE-PWM) [23] or staircase modulation [24] can also be applied to the MMC. SHE-PWM can reduce the switching frequency of the SMs and it also provides good harmonic performance [23]. However, complexity of implementation and calculation of angles increases significantly as the number of voltage levels increases.

Application of staircase modulation to an MMC with one hundred SMs per arm shows that when the number of SMs is large, the THD of the output voltage can be similar to that using CB-PWM [25]. Refs. [19], [22] have investigated the application of CB-PWM without and with carrier interleaving and the presented results show that carrier interleaving improves the THD of the output voltage at the expense of higher rms arm current. CB-PWM was also investigated in [20] for HVDC applications where a PS-PWM with voltage sorting algorithm was shown to provide lower capacitors voltage ripples compared to the PD-PWM and phase-opposition-disposition (POD-PWM).

The objective of this paper is to propose a low complexity voltage balancing algorithm for the MMC producing low switching frequency to the power devices. The paper also reports the performance of staircase and PD-PWM techniques under the conventional and proposed voltage balancing when applied to MMCs with relatively low number of SMs per arm.

The paper is organised as follows. In Section II, the MMC circuit, circulating current control and modulation techniques are introduced. The proposed voltage balancing algorithm is analysed in Section III together with a number of working examples that illustrate its operation. Simulation and experimental results are presented in Section IV. The conclusions of the work are summarised in Section V.

\section{MMC, Circulating CurRent CONTROL AND Modulation TECHNiQues}

The circuit configuration of the MMC has been well described in the existing literature [3], [4]. One phase-leg of the MMC includes $N$ SMs per arm in series and one inductor $(L)$; the function of $L$ is to limit the circulating current and the dc fault current within the phase-legs. The SM capacitor voltages in the upper and lower arms are defined as $v_{C u p j}$ and $v_{\text {Clowj }}$ for $j=\{1,2, \ldots, N\}$ and the voltages applied to the upper extreme of the upper inductor and the lower extreme of

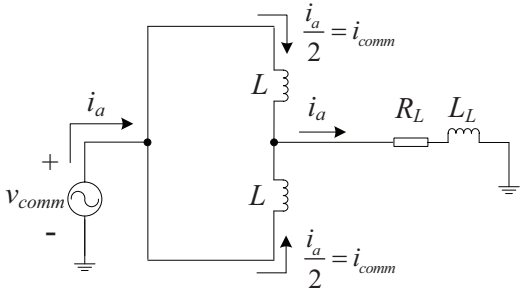

(a)

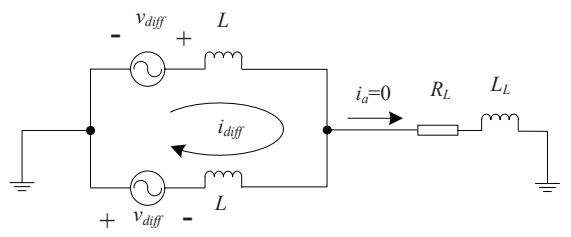

(b)

Fig. 2. (a) Common mode and (b) differential mode circuits.

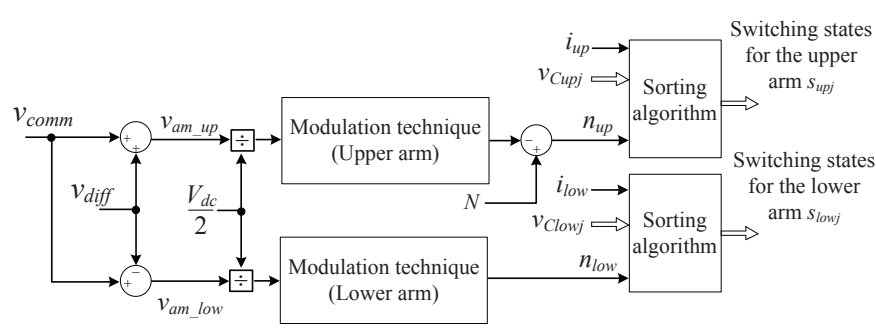

Fig. 3. A phase-leg modulation strategy for the upper and the lower arm including SMs capacitor voltage balancing for the MMC.

the lower inductor are defined as $v_{u p}$ and $v_{l o w}$, respectively (Fig. 1).

The analysis of the MMC, based on the theory of superposition, can be separated into two independent circuits, a common mode (Fig. 2(a)) and a differential mode (Fig. 2(b)). The common mode current $i_{\text {comm }}$ is equal to $i_{a} / 2$ while the differential $i_{\text {diff } f}$ is the current that circulates within the phase-legs of the MMC. Detailed analysis of the output and circulating current control can be found in the available technical literature [5], [9], [11], [26]. In this paper, a direct control of the circulating current and elimination of the ac components [22] is applied.

A characteristic of PWM for the MMC with a sorting-based voltage balancing algorithm is that the modulation is not directly associated with the switching of specific SMs as it only defines the total number of SMs to be activated in the upper and lower arms $\left(n_{u p}\right.$ and $n_{\text {low }}$ for $\left.n_{u p}, n_{\text {low }}=\{0,1, \ldots, N\}\right)$ (Fig. 3). In this study, staircase and PD-PWM are both applied to an MMC with twelve SMs per arm $(N=12)$. PD-PWM uses $N$ carriers displaced to occupy equal bands within the modulation index range [19] and both modulation techniques generate $N+1$ voltage levels. Both modulation techniques can also produce $2 N+1$ voltage levels by interleaving the transitions between the upper and lower arms [19], [22], but this modulation technique is not considered in this work. 


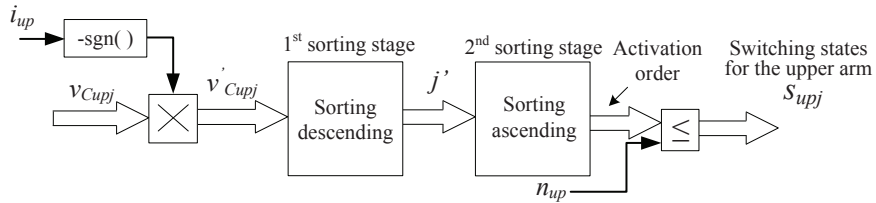

(a)

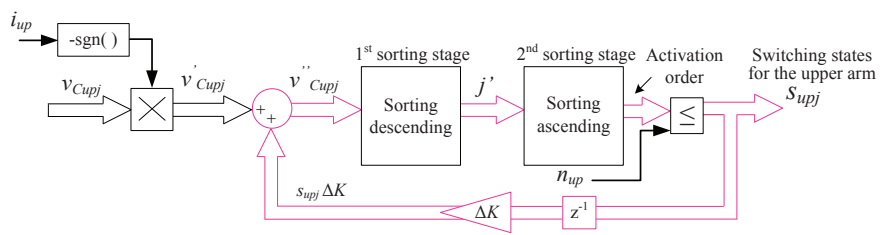

(b)

Fig. 4. Implementation of the proposed voltage balancing algorithm for the upper arm: (a) conventional and (b) restricted.

\section{Voltage Balancing Algorithm For the MMC}

\section{A. Sorting Stage}

The proposed algorithm uses two cascaded index sorting structures and a simple comparator for the selection of the SMs and generation of the arm switching states. Fig. 4(a) shows the voltage balancing algorithm applied to the upper arm. The diagram will be similar for the lower arm.

As a first step, the capacitor voltages are multiplied with the sign of the arm current under the convention that a positive sign denotes a current within the arm that charges the SM capacitors. The modified SM capacitor voltages $\left(v_{C u p j}^{\prime}\right)$ are:

$$
v_{C u p j}^{\prime}=-\operatorname{sgn}\left(i_{u p}\right) \cdot v_{C u p j},
$$

The first sorting stage uses the modified SM capacitor voltage measurements $\left(v_{C u p j}^{\prime}\right)$ and sorts the SM indices $(j)$ in a descending manner, providing a sorted list of indices based on SM voltages $\left(j^{\prime}\right)$ from the highest to the lowest input values as derived from (1). The second sorting stage uses the output of the first $\left(j^{\prime}\right)$ as input, based on ascending order. The output of the second stage indicates the activation order of each SM and the elements of the list directly relate to a particular SM with the first element indicating the activation order of $\mathrm{SM}_{u p 1}$ and the $N^{t h}$ element indicating the activation order of $\mathrm{SM}_{u p N}$. The SMs that need to be connected are those with an activation order below or equal to the number of required SMs $\left(n_{u p}\right)$ as defined by the modulation stage. A simple logical comparison of the activation order with $n_{u p}$ provides the SM switching states for the arm.

\section{B. Restricted Voltage Balancing Algorithm}

The direct implementation of the algorithm presented in Sub-section III-A creates additional switching transitions due to the variation of the SM capacitor voltages within a switching period, effectively increasing the switching frequency and associated losses without any additional gain in the converter output voltage. This sub-section describes a restriction in the number of SMs that are connected or bypassed at any given sampling instant (Fig. 4(b)) with the goal of reducing the SM switching frequencies.
The proposed algorithm achieves the reduction through a modification of the measured capacitor voltages $\left(v_{C u p j}^{\prime}\right)$ before they are introduced to the sorting stages of Sub-section III-A. A constant voltage offset $\Delta K$ multiplied with the switching states $\left(s_{u p j}=\{0,1\}\right)$ provides a fictitious separation between the voltages of the connected and bypassed SMs. The virtual SM capacitor voltages seen by the sorting stage are:

$$
v_{C u p j}^{\prime \prime}=v_{C u p j}^{\prime}+s_{u p j} \Delta K,
$$

so that the connected SMs $\left(s_{u p j}=1\right)$ have a voltage of:

$$
v_{C u p j}^{\prime \prime}=v_{C u p j}^{\prime}+\Delta K \text {, }
$$

while for the bypassed SMs $\left(s_{u p j}=0\right)$ :

$$
v_{C u p j}^{\prime \prime}=v_{C u p j}^{\prime} \text {. }
$$

$\Delta K$ must be chosen sufficiently large to provide the necessary separation between the voltage values of connected and bypassed SMs at any operating conditions and regardless of the $\mathrm{SM}$ capacitor voltage ripple. A value at least equal to $V_{d c} / N$ is suggested.

\section{Application and Working Examples}

The concepts and operation of the proposed algorithm can be illustrated through two working examples in an MMC with $N=5$ SMs per arm. The first example highlights how the sorting stages determine the candidate SMs that will be connected or bypassed at a given time instant depending on the arm current direction and the change in the number of required SMs in the arm. The second example demonstrates the reduction in the SM switching frequency over multiple time instants.

In the first example, the SM voltages $\left(v_{C u p j}\right)$ are that of Fig. 5 and the MMC is assumed to have two SMs $\left(\mathrm{SM}_{u p 2}\right.$ and $\mathrm{SM}_{u p 4}$ ) already connected to the upper arm at the given time instant. When the current through the arm is in the charging direction, the candidate SMs should include the most charged connected SM (in case $n_{u p}$ decreases) and the least charged bypassed one (in case $n_{u p}$ increases) [6]. When $\operatorname{sgn}\left(i_{u p}\right)=$ 1 , the output of the first sorting stage $\left(j^{\prime}\right)$ provides the list of SMs from the most to the least charged (Fig. 5(a)) already considering the voltage offset $\Delta K$. Based on $j^{\prime}$, the activation order of SMs is determined by the second sorting stage also shown in Fig. 5(a). The connected SMs at the given time instant are those based on the comparison of the activation order with $n_{u p}\left(\mathrm{SM}_{u p 2}\right.$ and $\left.\mathrm{SM}_{u p 4}\right)$. The choice of whether a SM will be connected or bypassed is defined by the change of $n_{u p}$ and if $n_{u p}$ increases $\left(n_{u p}=3\right) \mathrm{SM}_{u p 3}$, as the least charged bypassed SM, is connected. On the other hand, if $n_{u p}$ decreases by $1\left(n_{u p}=1\right), \mathrm{SM}_{u p 4}$ as the most charged connected $\mathrm{SM}$ will be bypassed. If $n_{u p}$ does not change at a given instant, the connected SMs remain the same.

Reversing the direction of the arm current (Fig. 5(b)) changes the virtual voltages $\left(v_{C u p j}^{\prime \prime}\right)$ seen by the first sorting stage and consequently the activation order of the SMs. The connected SMs remain the same with the initial assumption $\left(\mathrm{SM}_{u p 2}\right.$ and $\left.\mathrm{SM}_{u p 4}\right)$ while the candidate $\mathrm{SMs}$ for a change of $n_{u p}$ by \pm 1 now include the most charged bypassed SM 


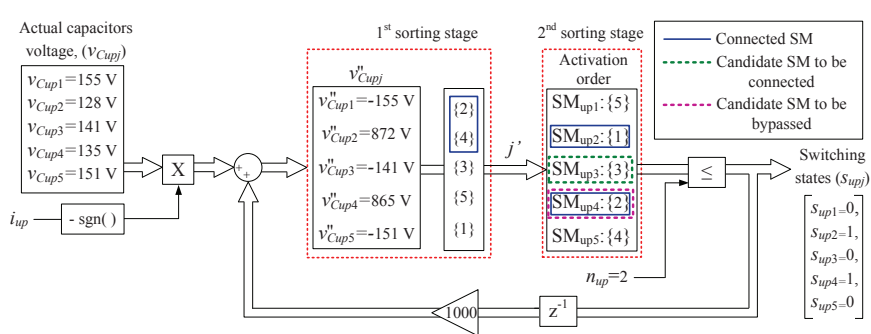

(a)

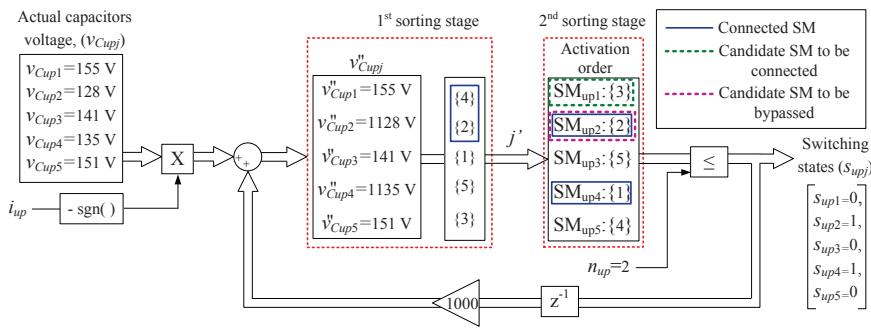

(b)

Fig. 5. Example of capacitor voltage balancing for one time interval when (a) the arm current is positive and (b) the arm current is negative.

$\left(\mathrm{SM}_{u p 1}\right)$ and the least charged connected $\mathrm{SM}\left(\mathrm{SM}_{u p 2}\right)$. Due to the voltage offset $\Delta K$, changes in the arm current direction only leads to a change in the activation order and does not force any change in the actual state (connected or bypassed) of a SM at a given time instant.

The second example shows the reduction of the SM switching frequency over multiple time instants by comparing the unrestricted algorithm with the proposed one (Fig. 6(a) and (b) respectively). Initially $\left(t_{0}\right)$, no SM is connected to the arm $\left(n_{u p}=0\right)$ while the direction of the arm current is assumed negative (discharging direction). At $t_{1}$ there is a change in the voltage level $\left(n_{u p}=1\right)$ and based on the arm current direction, the most charged SM $\left(\mathrm{SM}_{u p 5}\right)$ is connected by both algorithms. At the next time instant $\left(t_{2}\right)$, there is no change in the voltage level but due to the SM voltage variation, the unrestricted algorithm will change the SM that is connected from $\mathrm{SM}_{u p 5}$ to $\mathrm{SM}_{u p 4}$. This is avoided in the proposed algorithm as $\Delta K$ provides sufficient separation between the virtual voltages $v_{C u p j}^{\prime \prime}$ seen by the sorting stages. Similarly, at $t_{3}$ there is another change in the voltage level $\left(n_{u p}=2\right)$ and the unrestricted algorithm will connect two SMs and bypass one SM due to both the voltage level change and SM capacitor voltage variation. In the proposed algorithm (Fig. 6(b)) only one SM $\left(\mathrm{SM}_{u p 4}\right)$ will change state. The accumulated transition count within the demonstrated interval is eight for the conventional algorithm while the proposed algorithm requires only two, demonstrating its effectiveness in reducing the SM switching frequency.

\section{Simulation And Experimental Results}

\section{A. Simulation Results}

One phase-leg of the MMC with twelve SMs per arm ( $N=12$ ) has been simulated to validate the proposed voltage balancing algorithm. Results and conclusions are similar for any multiphase and multilevel configuration. The simulation

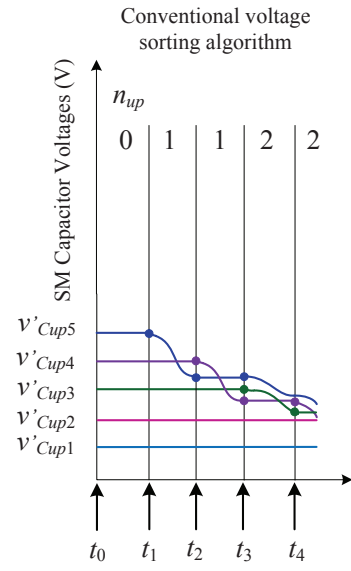

(a)

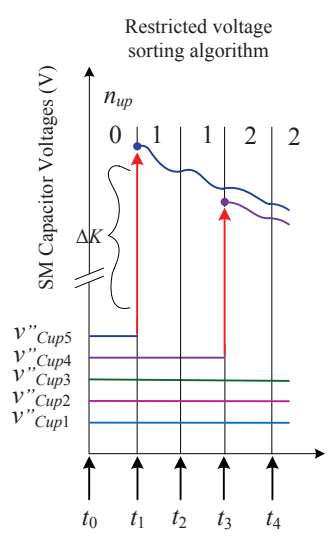

(b)
Fig. 6. Capacitors voltages balancing: (a) conventional and (b) restricted voltage sorting algorithm.

TABLE I

MMC SIMULATION PARAMETERS

\begin{tabular}{c|c}
\hline Parameter & Value \\
\hline \hline Number of SMs per arm, $N$ & 12 \\
\hline Dc-link voltage, $V_{d c}$ & $6000 \mathrm{~V}$ \\
\hline SM reference voltage, $V_{C}$ & $500 \mathrm{~V}$ \\
\hline SM capacitor, $C$ & $1.5 \mathrm{mF}$ \\
\hline Arm inductors, $L$ & $18 \mathrm{mH}$ \\
\hline Carrier frequency, $f_{c}$ & $4 \mathrm{kHz}$ \\
\hline Modulation index, $m_{a}$ & 0.95 \\
\hline \hline
\end{tabular}

parameters are shown in Table I; the dc-link voltage is assumed constant, no dc-link voltage control is considered. Four cases are considered in the simulations; the conventional and the restricted voltage balancing algorithm with both staircase modulation and PD-PWM. The sampling time for the staircase modulation is half of the period of the carrier frequency $\left(f_{c}\right)$ of PD-PWM. As a result, practically the same switching frequency in the power devices is produced for staircase modulation with conventional algorithm and PD-PWM with the restricted algorithm. Under these conditions, the capacitor voltage ripple amplitudes are very similar in both cases.

The arm currents are shown in Figs. 7(a) and (b) for the staircase modulation and in Figs. 7(c) and (d) the PD-PWM. Staircase modulation produces higher circulating current ripple than PD-PWM in both cases, mainly due to the bang-bang operation of the circulating current control in the case of staircase modulation. As a result, the rms values of the circulating currents in staircase modulation are larger resulting in higher losses to the power devices of the MMC.

Table II summarises the average switching frequency of the power devices, weighted total harmonic distortion (\%WTHD) of the common output voltage $\left.\left(v_{\text {comm }}=\left(v_{\text {up }}+v_{\text {low }}\right) / 2\right)\right)$ and peak-to-peak capacitor voltage $\left(v_{C u p j \_p p}\right)$ for all simulated cases. Comparing the conventional staircase modulation with the restricted PD-PWM where the average switching frequencies of the power devices assume similar values, it is concluded that PD-PWM yields better harmonic performance because under PD-PWM the SMs are connected and bypassed more 


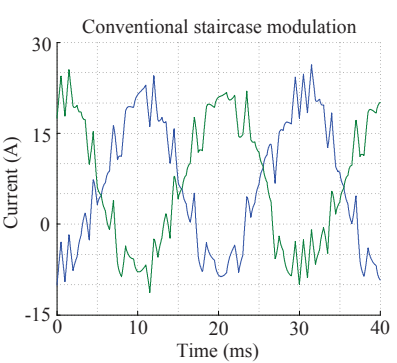

(a)

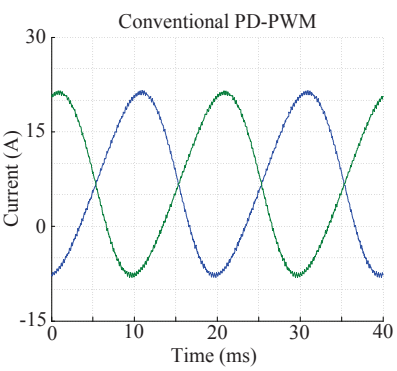

(c)

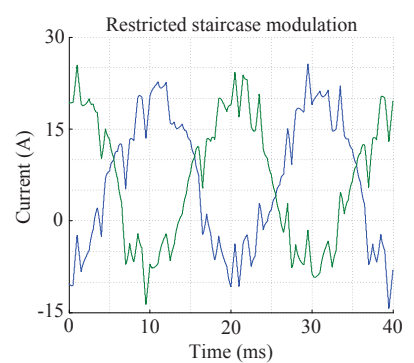

(b)

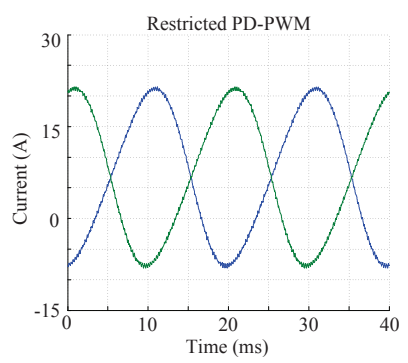

(d)
Fig. 7. Simulated upper and lower arm currents $\left(i_{u p}\right.$ and $\left.i_{l o w}\right)$ : (a) conventional voltage balancing algorithm with staircase modulation, (b) restricted voltage balancing algorithm with staircase modulation, (c) conventional voltage balancing algorithm with PD-PWM and (d) restricted voltage balancing algorithm with PD-PWM.

TABLE II

SUMMARIES OF SIMULATION RESULTS

\begin{tabular}{|l|c|c|c|}
\hline $\begin{array}{l}\text { Modulation } \\
\text { Technique }\end{array}$ & $\begin{array}{l}\text { Switching } \\
\text { Frequency (Hz) }\end{array}$ & \%WTHD & $\begin{array}{l}\text { Capacitor Voltage } \\
\text { Ripple (\%) }\end{array}$ \\
\hline $\begin{array}{l}\text { Conventional } \\
\text { staircase }\end{array}$ & 382 & 0.431 & 5.052 \\
\hline $\begin{array}{l}\text { Restricted } \\
\text { staircase }\end{array}$ & 60 & 0.464 & 10.039 \\
\hline $\begin{array}{l}\text { Conventional } \\
\text { PD-PWM }\end{array}$ & 1028 & 0.163 & 4.207 \\
\hline $\begin{array}{l}\text { Restricted } \\
\text { PD-PWM }\end{array}$ & 380 & 0.174 & 4.339 \\
\hline
\end{tabular}

frequently compared to the restricted staircase modulation technique (Fig. 8). Fig. 8 also shows the transitions for the other two modulating techniques confirming the fundamental switching frequency of SMs under restricted staircase modulation (Fig. 8(a)) and the excessive switching frequency caused by the conventional PD-PWM (Fig. 8(b)).

The SM capacitor voltage waveforms are illustrated in Fig. 9. The restricted voltage balancing algorithm affects the amplitude of the capacitors voltage ripples especially with staircase. This is because in the case of restricted staircase modulation, the SMs are allowed to be connected/bypassed only about once per half a period, producing the highest capacitors voltage ripples. The similar switching frequency of conventional staircase and restricted PD-PWM results in similar SM capacitor voltage ripple. Finally, comparing the two voltage balancing algorithms under PD-PWM, the conventional voltage balancing algorithm produces slightly lower capacitors voltage ripples albeit with significantly higher switching frequencies.

The switching frequency is calculated through the cumula-

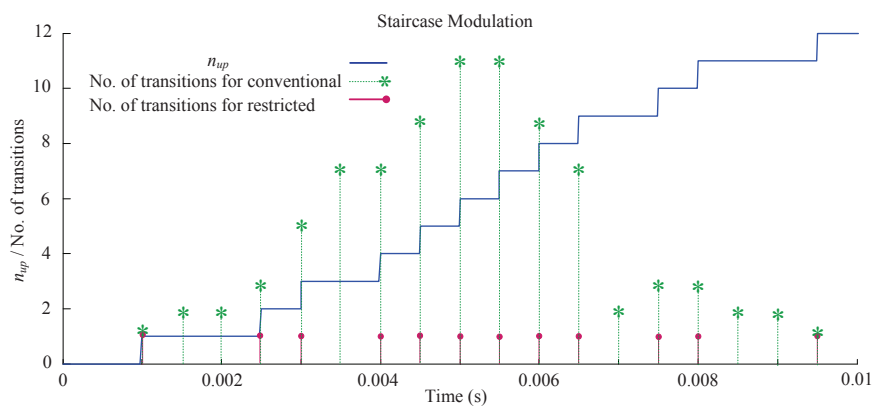

(a)

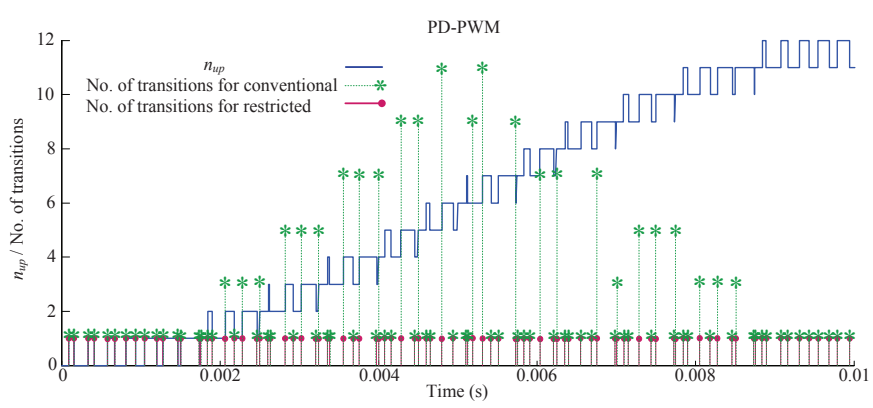

(b)

Fig. 8. Required number of SMs in the upper arm $\left(n_{u p}\right)$ and number of transitions over half of the fundamental period: (a) conventional and restricted staircase modulation and (b) conventional and restricted PD-PWM.

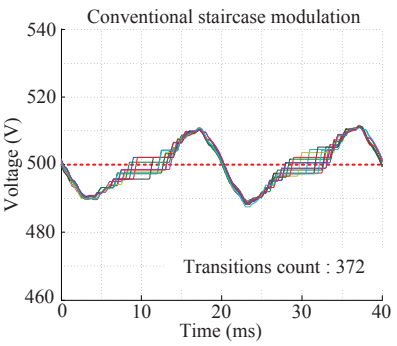

(a)

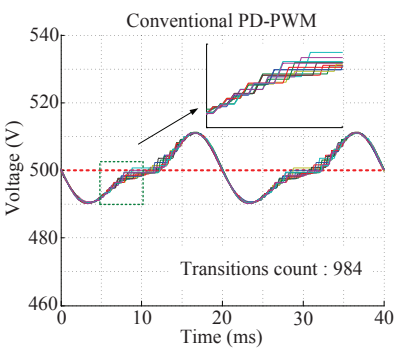

(c)

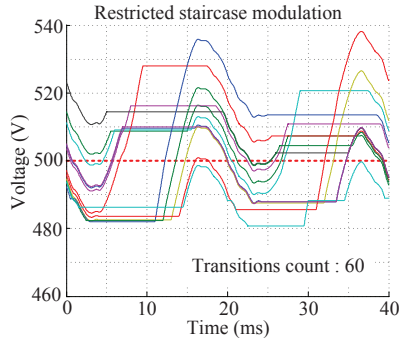

(b)

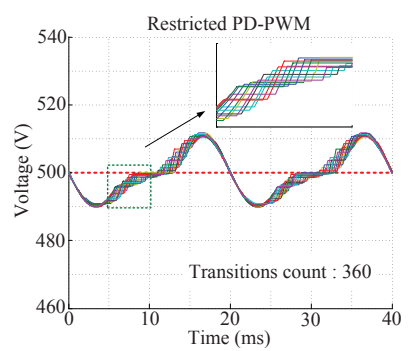

(d)
Fig. 9. Simulated SM capacitors voltages $\left(v_{C u p j}\right)$ : (a) conventional voltage balancing algorithm with staircase modulation, (b) restricted balancing algorithm with staircase modulation, (c) conventional voltage balancing algorithm with PD-PWM, and (d) restricted voltage balancing algorithm with PD-PWM.

tive count of transitions within one arm of the MMC (Fig. 10). Although, the switching frequency is not constant, an average value can be defined as the slope of the line that approximates the transition count for a certain time period. The average switching frequency of the SMs over a time interval $\Delta t$ is:

$$
f_{s w}=\frac{\text { Transitions count }}{2 N \cdot \Delta t}
$$




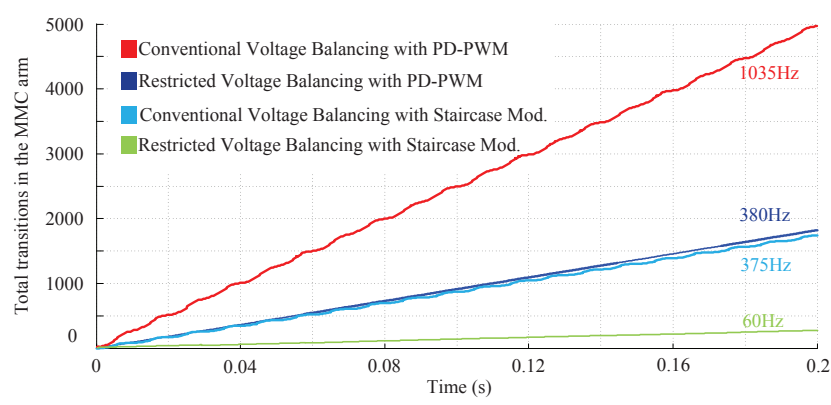

Fig. 10. Total number of transitions and average SM switching frequencies in the simulation with staircase modulation and PD-PWM.

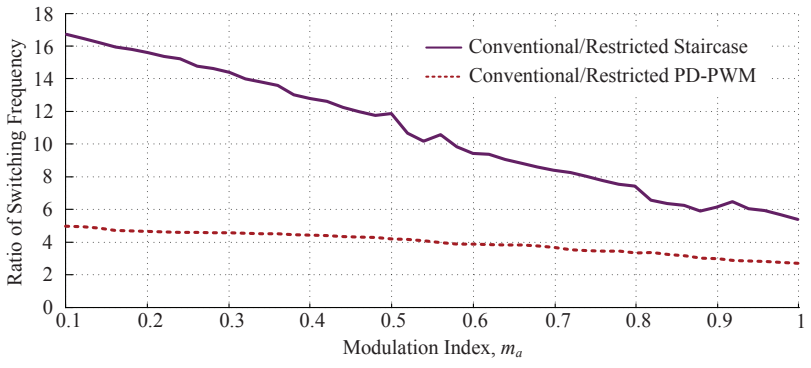

Fig. 11. Ratio of the average switching frequencies of one SM.

The effect of the proposed algorithm is also clearly demonstrated with the total number of transitions for all of the cases. This calculation can be extended for all possible operating points of the MMC, i.e. modulation index $\left(m_{a}\right)$ and load phase angle, $(\varphi)$, under all possible modulation techniques through extensive simulations. It is evident that the proposed algorithm reduces the switching frequency of the SMs significantly, as shown by the ratio of the average SM switching frequency of the conventional and restricted voltage balancing algorithms for both staircase modulation and PD-PWM (Fig. 11). The load phase angle does not have a significant effect in the switching frequency although the SM voltage ripple and rms arm currents will vary depending on the particular operating point [27]. Comparing the conventional staircase with the restricted PWM (Fig. 12), an overall lower average switching frequency can be achieved for the PWM with significant gains particularly in low modulation indices.

\section{B. Experimental Verification}

The proposed algorithm is experimentally verified in a laboratory prototype of a phase-leg MMC with five SMs perarm (Table III) as shown in Fig. 13 [23]. The arm currents (Fig. 14) under staircase modulation exhibit higher ripples than under PD-PWM. The restriction in the transitions does not have a significant impact on the arm currents under the same modulation technique, in agreement with Fig. 7, showing that the excessive switching of conventional voltage balancing algorithms does not benefit the MMC further.

The experimental results for the capacitors voltages (Fig. 15) are also in close agreement with the simulation and one can observe that the restricted staircase PWM produces the highest peak-to-peak voltage ripple $\left(5 \mathrm{~V}_{p p}\right)$ while the

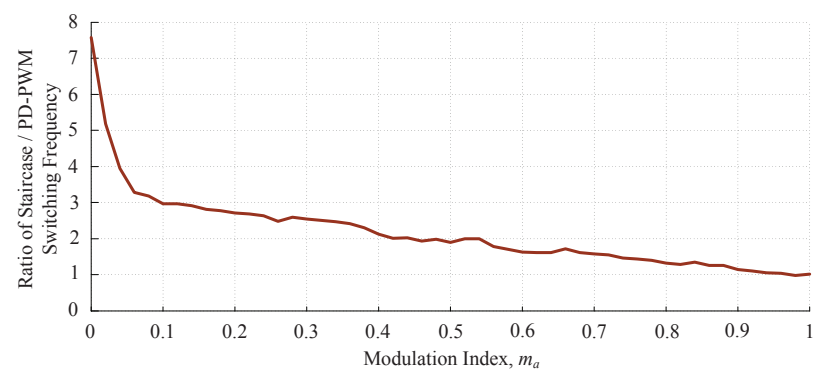

Fig. 12. Ratio of the average switching frequencies: conventional staircase over restricted PD-PWM.

TABLE III

MMC EXPERIMENTAL PROTOTYPE PARAMETERS

\begin{tabular}{c|c}
\hline Parameter & Value \\
\hline \hline Number of SMs per arm, $N$ & 5 \\
\hline Dc-link voltage, $V_{d c}$ & $300 \mathrm{~V}$ \\
\hline SM reference voltage, $V_{C}$ & $60 \mathrm{~V}$ \\
\hline SM capacitor, $C$ & $3.6 \mathrm{mF}$ \\
\hline Arm inductors, $L$ & $3.6 \mathrm{mH}$ \\
\hline Carrier frequency, $f_{c}$ & $4 \mathrm{kHz}$ \\
\hline Load resistor, $R_{L}$ & $31 \Omega$ \\
\hline Load inductor, $L_{L}$ & $5 \mathrm{mH}$ \\
\hline \hline
\end{tabular}

conventional PD-PWM has the lowest $\left(2.5 \mathrm{~V}_{p p}\right)$. On the other hand conventional staircase and restricted PD-PWM, which exhibit similar average switching frequency, produce similar ripple $\left(3.5 \mathrm{~V}_{p p}\right)$. The cumulative transition count within the MMC arms for all four cases, also illustrating the switching frequencies of the experimental results, are shown in Fig. 16 verifying the theoretical analysis and simulation results of Fig. 10.

\section{CONCLUSION}

In this paper, a simple implementation of voltage balancing algorithm aiming at reducing the switching frequency of the power devices of an MMC has been presented. The algorithm can easily switch from the restricted mode to the conventional one by imposing the voltage offset value of the parameter $\Delta K$ to zero. The proposed algorithm has been applied to two modulation strategies, staircase modulation and PD-PWM and tested by simulation on an MMC with $12 \mathrm{SMs}$ per arm $(N=12)$ and experimentally on an MMC with $5 \mathrm{SMs}$ per arm $(N=5)$. The results show that PD-PWM performs generally better than staircase modulation under similar switching frequency conditions, since it produces circulating currents with less ripple and output voltages with lower WTHD values.

The conventional and restricted voltage balancing algorithms with PD-PWM produce similar capacitor voltage ripples, while the restricted algorithm reduces significantly the switching frequency of the power devices. On the other hand, when the restricted algorithm is applied to staircase modulation, the switching frequency is also reduced, but the capacitor voltage ripples increase significantly. In terms of the arm currents, PD-PWM always produces less current ripples than staircase modulation in both cases. The differences between staircase modulation and PD-PWM become significant for 


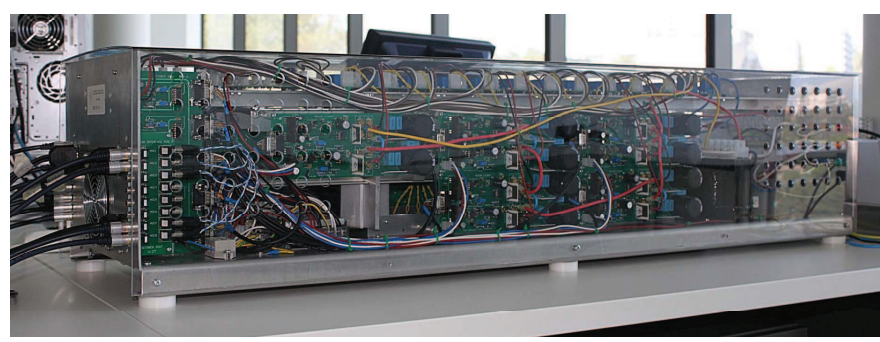

Fig. 13. Laboratory prototype of a phase-leg MMC with $N=5 \mathrm{SMs}$ per arm

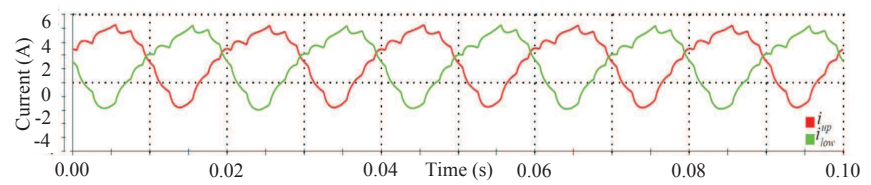

(a)

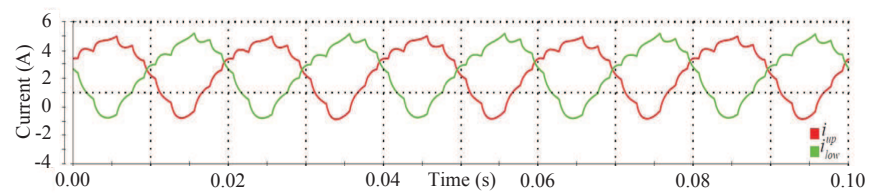

(b)

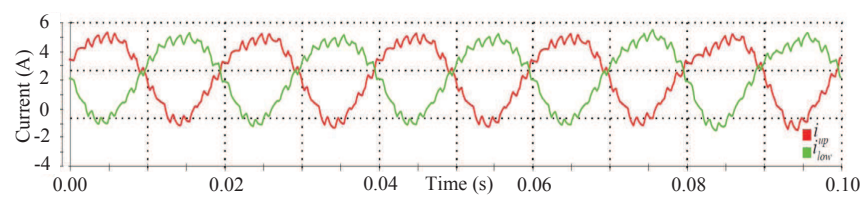

(c)

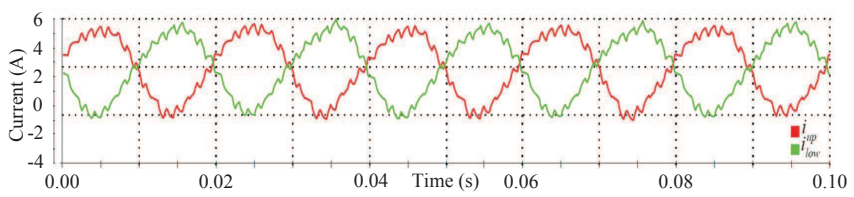

(d)

Fig. 14. Experimental results of arm currents: (a) conventional staircase, (b) restricted staircase, (c) conventional PD-PWM, and (d) restricted PD-PWM.

MMCs with a relatively low number of SMs per arm, but tend to diminish as the number of SMs increases.

\section{REFERENCES}

[1] A. Lesnicar and R. Marquardt, "An innovative modular multilevel converter topology suitable for a wide power range," in Proc. IEEE Bolognia Power Tech. Conf., Jun 2003.

[2] J. Gerdes. (2011) Siemens debuts HVDC PLUS with san franciscos's trans bay cable. Available: http//www.energy.siemens.com/n1/pool/hq/energytopics/living-energy/issue-5/LivingEnergy_05_hvdc.pdf

[3] R. Marquardt, "Modular multilevel converter: An universal concept for HVDC-networks and extended dc-bus-applications," in Proc. IEEE IPEC 2010 , pp. $502-507$.

[4] R. Marquardt, "Modular multilevel converter topologies with DC-shor circuit current limitation," in Proc. IEEE ICPE 2011, pp. 1425-1431.

[5] S. Xu and A. Huang, "Circulating current control of double-star choppercell modular multilevel converter for HVDC system," in Proc. IEEE IECON 2012, pp. 1234-1239.

[6] M. Saeedifard and R. Iravani, "Dynamic performance of a modular multilevel back-to-back HVDC system," IEEE Trans. Power Del., vol. 25 , no. 4, pp. 2903-2912, Oct. 2010

[7] D. Peftitsis, G. Tolstoy, A. Antonopoulos, J. Rabkowski, J.-K. Lim, M Bakowski, L. Angquist, and H. P. Nee, "High-power modular multilevel converters with SiC JFETs," IEEE Trans. on Power Electron., vol. 27, no. 1, pp. 28-36, Jan. 2012.

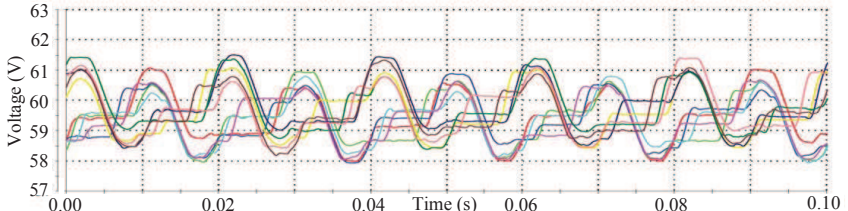

(a)

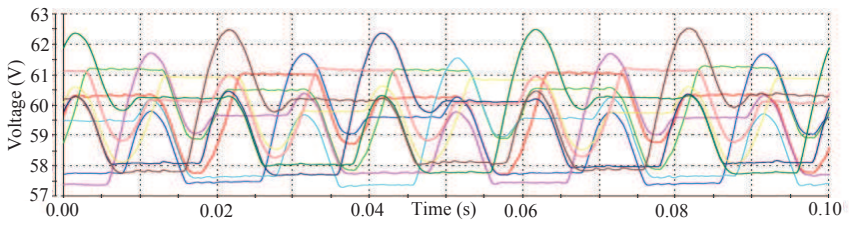

(b)

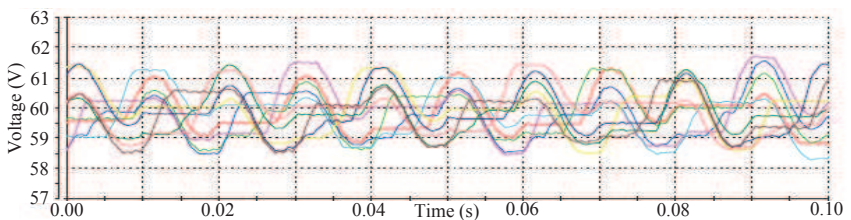

(c)

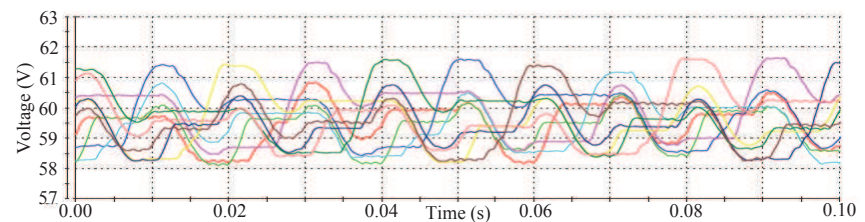

(d)

Fig. 15. Experimental results of capacitor voltages: (a) conventional staircase (b) restricted staircase, (c) conventional PD-PWM and (d) restricted PD-PWM.

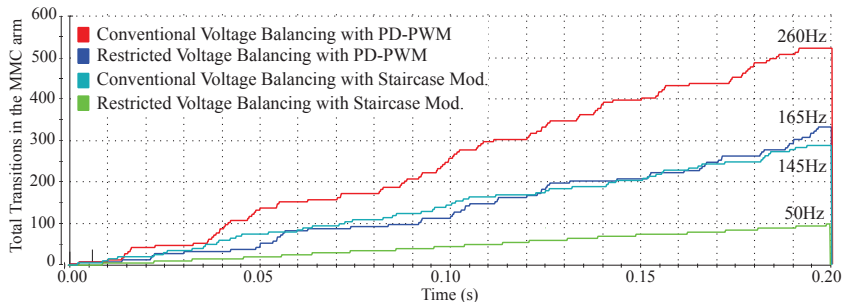

Fig. 16. Total number of transitions and average SM switching frequencies in the laboratory prototype with staircase modulation and PD-PWM.

[8] F. Deng and Z. Chen, "Control method for voltage balancing in modular multilevel converters," IEEE Trans. Power Electron., vol. 29, no. 1, pp. 66-76, Jan. 2014

[9] J. W. Moon, C. S. Kim, J. W. Park, D. W. Kang, and J. M. Kim, "Circulating current control in MMC under the unbalanced voltage," in IEEE Trans. Power Del., vol. 28, no. 3, pp. 1952-1959, Oct. 2013.

[10] Q. Jiangchao and M. Saeedifard, "Predictive control of a modular multilevel converter for a back-to-back HVDC system," IEEE Trans. Power Del., vol. 27, no. 3, pp. 1538-1547, Jul. 2012.

[11] M. Hagiwara, R. Maeda, and H. Akagi, "Theoretical analysis and control of the modular multilevel cascade converter based on double-star choppercells (MMCC-DSCC)," in Proc. IEEE IPEC 2010, pp. 2029-2036.

[12] K. Ilves, L. Harnefors, S. Norrga, and H. P. Nee, "Predictive sorting algorithm for multilevel converters minimizing the spread in the submodule capacitor voltages," in Proc. IEEE ECCE Asia, Jun 2013, pp. 325-331.

[13] S. Du, J. Liu, and T. Liu, "Modulation and close-loop based DC capacitor voltage control for MMC with fundamental switching frequency," IEEE Trans. Power Electron. early access, DOI: 10.1109/TPEL2014.2301836.

[14] D. Siemaszko, "Fast sorting method for balancing capacitor voltages in modular multilevel converter," IEEE Trans. Power Electron. early access, DOI: 10.1109/TPEL2014.2312101. 
[15] S. Fan, K. Zhang, J. Xiong, and Y. Xue, "An improved control system for modular multilevel converters with new modulation strategy and voltage balancing control," IEEE Trans. Power Electron. early access, DOI: 10.1109/TPEL2014.2304969.

[16] J. Qin and M. Saeedifard, "Reduced switching frequency voltage balancing strategies for modular multilevel HVDC converters," IEEE Trans. Power Del., vol. 28, no. 4, pp. 2403-2410, Oct. 2013.

[17] T. Qingrui, X. Zheng, and X. Lie, "Reduced switching-frequency modulation and circulating current suppression for modular multilevel converters," IEEE Trans. Power Del., vol. 26, no. 3, pp. 2009-2017, Jul. 2011.

[18] G. Minyuan, X. Zheng, and C. Hairong, "Control and modulation strategies for modular multilevel converter based HVDC system," Proc. IEEE IECON, 2011, pp. 849-854.

[19] G. Konstantinou and V. G. Agelidis, "Performance evaluation of halfbridge cascaded multilevel converters operated with multicarrier sinusoidal PWM techniques," in Proc. IEEE ICIEA, 2009, pp. 3399-3404.

[20] A. Hassanpoor, S. Norrga, H. Nee, and L. Angquist, "Evaluation of different carrier-based PWM methods for modular multilevel converters for HVDC application," in Proc. IEEE IECON, 2012, pp. 388-393.

[21] M. Jun, X. Bailu, S. Ke, L. M. Tolbert, and Z. Jian Yong, "Modular multilevel inverter with new modulation method and its application to photovoltaic grid-connected generator," IEEE Trans. Power Electron., vol. 28, no. 11, pp. 5063-5073, Nov. 2013.

[22] R. Darus, J. Pou, G. Konstantinou, S. Ceballos, and V. G. Agelidis, "Circulating current control and evaluation of carrier dispositions in modular multilevel converters," in Proc. IEEE ECCE Asia, Jun. 2013, pp. 332-338.

[23] G. Konstantinou, M. Ciobotaru, and V. G. Agelidis, "Selective harmonic elimination pulse width modulation of the modular multilevel converter," IET Power Electron., vol. 6, Iss. 1, pp. 1-12, Jan. 2013.

[24] K. Ilves, A. Antonopoulos, S. Norrga, and H. P. Nee, "A new modulation method for the modular multilevel converter allowing fundamental switching frequency," IEEE Trans. Power Electron., vol. 27, no. 8, pp. 3482-3494, Aug. 2012

[25] Z. Jianfei, G. Chun, C. Kai, Y. Xingwu, M. Wenzhe, and J. Jianguo, "Research on high-voltage large-capacity modular multilevel converter (MMC) system," in Proc. IEEE ISDEA, 2012, pp. 1470-1474.

[26] J. Pou, S. Ceballos, G. Konstantinou, G. J. Capella, and V. G. Agelidis, "Control strategy to balance operation of parallel connected legs of modular multilevel converters," in Proc. IEEE ISIE, May 2013, pp.1-7.

[27] J. Pou, S. Ceballos, G. Konstantinou, V. G. Agelidis, R. Picas, and J. Zaragoza, "Circulating current injection methods based on instantaneous information for the modular multilevel converter," IEEE Trans. Ind. Electron. early access, DOI 10.1109/TIE.2014.2336608.

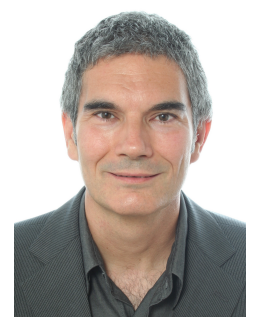

Josep Pou (S97-M03-SM13) received the B.S. M.S., and Ph.D. degrees in electrical engineering from the Technical University of Catalonia (UPC), Spain, in 1989, 1996, and 2002, respectively. In 1990, he joined the faculty of UPC as an Assistant Professor, where he became an Associate Professor in 1993. Since February 2013, he is a Professor with the University of New South Wales (UNSW), Sydney, on a leave from the UPC, where he keeps a permanent position. From February 2001 to January 2002, and February 2005 to January 2006, he was a Researcher at the Center for Power Electronics Systems, Virginia Tech, Blacksburg. From January 2012 to January 2013, he was a Researcher at the Australian Energy Research Institute, UNSW, Sydney. From 2006 to 2013, he collaborated with TECNALIA Research \& Innovation as a research consultant. He has authored more than 170 published technical papers and has been involved in several industrial projects and educational programs in the fields of power electronics and systems. His research interests include multilevel converters, renewable energy generation, and HVDC transmission systems. Dr. Pou is a member of the IEEE Industrial Electronics and the IEEE Power Electronics Societies.

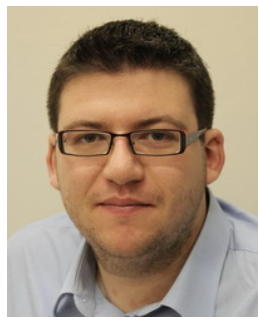

Georgios Konstantinou (S'08-M'13) received the B.Eng. degree in electrical and computer engineering from the Aristotle University of Thessaloniki, Thessaloniki, Greece, in 2007 and the Ph.D. degree in electrical engineering from the University of New South Wales (UNSW), Sydney, Australia, in 2012 $\mathrm{He}$ is currently a Senior Research Associate with the Australian Energy Research Institute and the School of Electrical Engineering and Telecommunications, UNSW. His research interests include hybrid and modular multilevel converters, pulse width modulation, and selective harmonic elimination techniques for power electronics. Dr. Konstantinou is an Associate Editor of IET Power Electronics.

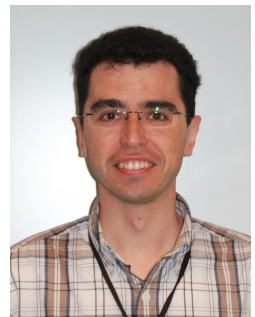

Salvador Ceballos received the M.S. degree in physics from the University of Cantabria, Santander, Spain, in 2001, and the M.S. and Ph.D. degrees in electronic engineering from the University of the Basque Country, Bilbao, Spain, in 2002 and 2008 respectively. Since 2002 he has been with Tecnalia Research and Innovation, where he is currently a researcher in the Energy and Environmental Division. From May 2008 to May 2009 he was a visiting researcher at the Hydraulic and Maritime Research Centre (HMRC) University College Cork (UCC) Cork, Ireland. He has authored more than 80 published technical papers. His research interests include multilevel converters, fault-tolerant power electronic topologies, and renewable energy systems.

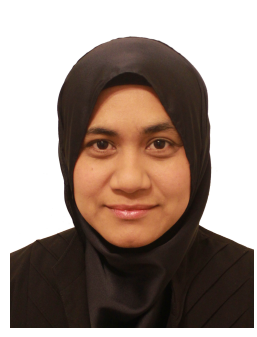

Rosheila Darus received her B.Eng. and M.Eng. from Universiti Teknologi Tun Hussein Onn (UTHM) Malaysia and Universiti Teknologi Malaysia (UTM) in 2005 and 2008 respectively. She joined Universiti Teknologi Mara (UiTM) Malaysia as a lecturer in the Faculty of Electrical Engineering in 2008 and she is currently pursuing her Ph.D. degree in the school of Electrical Engineering and Telecommunications, University of New South Wales (UNSW), Sydney, Australia. He research interests include modulation and control of the modular multilevel converter (MMC).

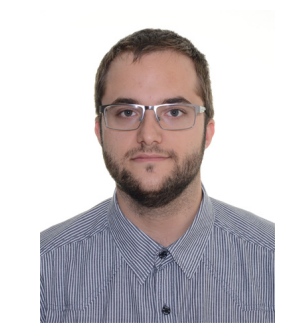

Ricard Picas (S'12) received the B.S. degree in electronic engineering and the M.S. degree in automatics and industrial electronics engineering from the Technical University of Catalonia (UPC), Terrassa, Spain, in 2010 and 2012, respectively. He is currently pursuing the Ph.D. degree at the UPC Since 2012 he is working with the Terrassa Industrial Electronics Group (TIEG) at UPC in Terrassa as a $\mathrm{Ph} . \mathrm{D}$. student. His main research interests include multilevel converters and HVDC systems. 


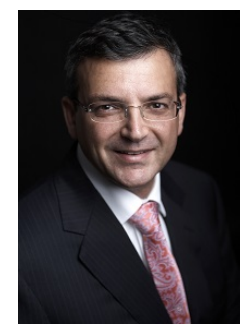

Vassilios G. Agelidis (SM'00) was born in Serres, Greece. He received the B.Eng. degree in electrical engineering from the Democritus University of Thrace, Thrace, Greece, in 1988; the M.S. degree in applied science from Concordia University, Montreal, QC, Canada, in 1992; and the Ph.D. degree in electrical engineering from Curtin University, Perth, Australia, in 1997.

$\mathrm{He}$ has worked with Curtin University (1993-1999); the University of Glasgow, Glasgow, U.K. (2000-2004); Murdoch University, Perth, Australia (2005-2006); and the University of Sydney, Sydney, Australia (2007-2010). He is currently the Director of the Australian Energy Research Institute, School of Electrical Engineering and Telecommunications, University of New South Wales, Sydney.

Dr. Agelidis was the recipient of the Advanced Research Fellowship from the U.K.'s Engineering and Physical Sciences Research Council in 2004. He was the Vice President for Operations with the IEEE Power Electronics Society (PELS) from 2006 to 2007 . He was an AdCom Member of IEEE PELS from 2007 to 2009 and the Technical Chair of the 39th IEEE Power Electronics Specialists Conference in 2008 held in Rhodes, Greece. 